\title{
A 45-year sub-annual reconstruction of seawater temperature in the Bay of Brest, France, using the shell oxygen isotope composition of the bivalve Glycymeris glycymeris
}

The Holocene

2020, Vol. 30(I) 3-12

(C) The Author(s) 2019

Article reuse guidelines:

sagepub.com/journals-permissions DOI: $10.1177 / 0959683619865592$ journals.sagepub.com/home/hol @SAGE

\author{
Amy M Featherstone, ${ }^{1,2}$ (iD Paul G Butler, ${ }^{3}$ Bernd R Schöne, ${ }^{4}$ \\ Melita Peharda ${ }^{5}$ and Julien Thébault'
}

\begin{abstract}
A reconstruction of sea surface temperature (SST) spanning 45 years (1966-20II) was developed from $\delta^{18} \mathrm{O}$ obtained from the aragonitic shells of Glycymeris glycymeris, collected from the Bay of Brest, France. Bivalve sampling was undertaken monthly between 2014 and 2015 using a dredge. In total, 40 I live specimens and 243 articulated paired valves from dead specimens were collected, of which 24 individuals were used to reconstruct SST. Temperatures determined using the palaeotemperature equation of Royer et al. compared well with observed SST during the growing season between 1998 and 2010 (Pearson's correlation: $p=0.002, r=0.760$ ). Furthermore, a significant negative correlation was found between the reconstructed SST and the North Atlantic Subpolar Gyre (SPG) index $(p=0.00 \mathrm{I}, r=-0.50)$, and a significant positive correlation was found with the East Atlantic Pattern (EAP) index when the reconstructed SST was lagged by I year $(p=0.002, r=0.46)$. This led to the conclusion that EAP and SPG are major influences on SSTs in the Bay of Brest. As the SPG controls air temperature in Northern Europe and the EAP controls water temperature in Southern Europe, this suggests that the Bay of Brest is an interaction area between these two climate systems. As such, this locality is interesting as the $\delta^{18} O$ of the shells can be used as a proxy for both the SPG and EAP, and temperature reconstructions can provide a unique insight into how these climate systems interacted prior to the instrumental era.
\end{abstract}

\section{Keywords}

aragonite, climate signals, dog cockle, EAP, high-resolution proxy records, NAO, sclerochemistry, sclerochronology, SPG, stable isotopes, temperature reconstruction

Received 16 July 2018; revised manuscript accepted 12 June 2019

\section{Introduction}

The reconstruction of past climates is important because it provides a long-term context for modern climate warming. Numerous studies have focused on climate change of the past few centuries to millennia, using both modelling experiments based on estimated climate forcings (Hansen et al., 1998; Meehl et al., 2007; Murphy et al., 2004; Seager et al., 2007) and empirical reconstructions using proxy data (Braconnot et al., 2012; Jones et al., 2013; Mann et al., 1998, 2009; Moberg et al., 2005). In addition, since the late 19th century, meteorological stations have been providing records of temperature, precipitation and other climate indicators over both the northern and southern hemispheres (Jones et al., 1998). Until recent decades, these records have been predominantly land-based, supplemented by ship-based logs of sea surface temperatures (SSTs; García-Herrera et al., 2005).

In order to study marine climate before the development of the robust instrumental record, evidence derived from relatively scarce marine climate proxies must be used (Butler et al., 2009, 2010; Pollack and Huang, 2000) The requirement for such reconstructions is precisely dated, high-resolution proxy data that can be calibrated with instrumental measurements (Mann et al., 1999). It is especially important to take account of the seasonality of the proxy data (Mann et al., 1998).

This study uses stable oxygen isotope data from the shell of the marine bivalve Glycymeris glycymeris from the Bay of Brest to reconstruct seawater temperatures for periods before the availability of local instrumental data (1998-present). It has been shown using oxygen isotopes (Berthou et al., 1986) that $G$. glycymeris growth increments are formed annually, with the

\footnotetext{
'Laboratoire des sciences de l'environnement marin (LEMAR UMR 6539 CNRS/UBO/IRD/lfremer), Institut Universitaire Européen de la Mer, Université de Bretagne Occidentale, France ${ }^{2}$ Department of Bioscience, Aarhus University, Denmark ${ }^{3}$ College of Life and Environmental Sciences, University of Exeter, UK ${ }^{4}$ Institute of Geosciences, University of Mainz, Germany ${ }^{5}$ Institute of Oceanography and Fisheries, Croatia
}

\section{Corresponding author:}

Amy M Featherstone, Department of Bioscience, Aarhus University, Ny Munkegade 116, 8000 Aarhus C, Denmark.

Email: amy.featherstonel@gmail.com 
narrow growth bands corresponding to periods of slower growth. Using these growth increments, it has previously been indicated that G. glycymeris can live up to two centuries (Reynolds et al., 2013). The longevity of G. glycymeris, together with the fact that it grows synchronously within populations (Brocas et al., 2013; Reynolds et al., 2013, 2017; Royer et al., 2013), make the shell of this species a suitable subject for palaeoenvironmental studies.

The specific objective of this study was to use stable oxygen isotope values in the shell $\left(\delta^{18} \mathrm{O}_{\text {shell }}\right)$ of $G$. glycymeris to investigate the drivers of seawater temperature in the Bay of Brest. In order to achieve this objective, the following goals were set: (1) to successfully reconstruct seawater temperatures further back in time than instrumental measurements, and (2) to identify relationships between the reconstructed temperature and the climate modes that are thought to influence the temperature in this study area (e.g. Tréguer et al., 2014). These climate modes include the North Atlantic Subpolar Gyre (SPG), East Atlantic Pattern (EAP) and North Atlantic Oscillation (NAO).

The NAO index is used to describe fluctuations in atmospheric pressure at sea level between the subpolar and subtropical regions (Hurrell et al., 2001). It is an indicator of weather patterns (wind, temperature, moisture, etc.) in the North Atlantic, especially the strength and direction of westerly winds and storm tracks during the winter months (Dawson et al., 2002). The NAO index used here is defined as the normalized pressure level difference between the Azores (high pressure) and Iceland (low pressure) (Hurrell et al., 2001). Here, we use the winter NAO index $\left(\mathrm{NAO}_{\text {winter }}\right.$; December, January, February) because, although shell growth is strongly reduced or halted completely over the months covered by $\mathrm{NAO}_{\text {winter }}$, some studies (such as Saunders et al., 2002, which looked in detail at summer snow extent) have shown that the European summer climate is significantly linked to $\mathrm{NAO}_{\text {winter }}$. The EAP is the second mode of climate variability in the North Atlantic and is more appropriate than the NAO as an indicator of conditions in southern Europe, including, SST, hydrological processes and mean precipitation rates (Tréguer et al., 2014). The SPG in the North Atlantic is formed by the North Atlantic Current in the south and the east and part of it propagates northwards, forming into the Norwegian Current (Herbaut and Houssais, 2009). The heat released from the Norwegian Current into the atmosphere maintains a mild climate in northern Europe (Bonan, 2008).

\section{Materials and methods}

\section{Shell collection and study site}

The Bay of Brest is a semi-enclosed marine ecosystem with an area of $180 \mathrm{~km}^{2}$ and an average depth of $8 \mathrm{~m}$. It is connected to the Atlantic shelf (Iroise Sea) by a strait to the west that is $2 \mathrm{~km}$ wide and $40 \mathrm{~m}$ deep and is fed by two rivers, the Aulne and the Elorn, which have catchment areas of 1822 and $280 \mathrm{~km}^{2}$, respectively. Together, these two rivers provide up to $85 \%$ of the total freshwater input into the bay (Raimonet et al., 2013).

Seawater temperature and salinity were monitored weekly from 1998 to present at the Service d'Observation en Milieu LITtoral (SOMLIT)-Brest station located at the outlet of the Bay of Brest (48 $21^{\prime} 30 \mathrm{~N}, 4^{\circ} 33^{\prime} 06 \mathrm{~W}$; Figure 1), using a Sea-Bird SBE 19 CTD profiler (Sea-Bird Electronics, Inc.). The buoy MARELIroise provides records of temperature, conductivity, dissolved oxygen, $\mathrm{pH}$ and turbidity, measured every $20 \mathrm{~min}$ at a location 50 $\mathrm{m}$ from the SOMLIT-Brest station since 1998.

The study site, the Banc de la Cormorandière $\left(48^{\circ} 20^{\prime} 26 \mathrm{~N}\right.$, $4^{\circ} 30^{\prime} 44 \mathrm{~W}$ ), is a subtidal dune subject to strong tidal currents and located in the western part of the Bay of Brest, near its outlet (Figure 1). G. glycymeris shells were collected monthly at this site between September 2014 and November 2015. In total, 401 living specimens and 243 paired valves of G. glycymeris were collected

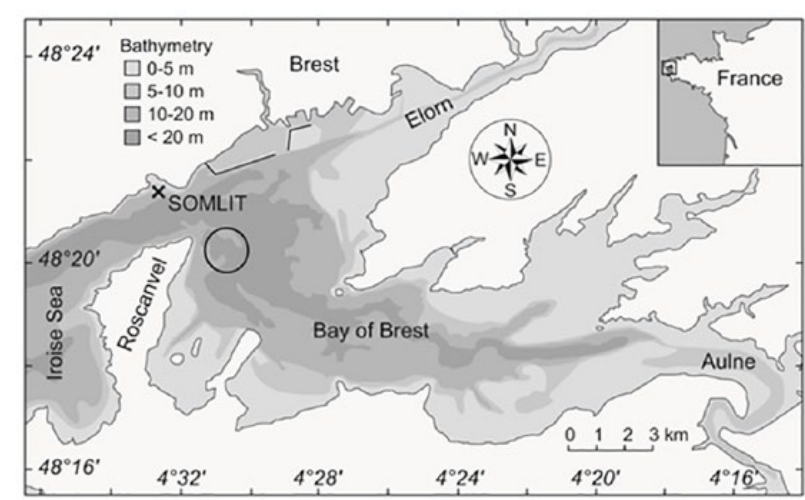

Figure I. Location of Brittany in France and sample location within Brittany. Circle indicates sample site and ' $X$ ' shows the position of SOMLIT-Brest research station.

Adapted from Thébault and Chavaud (2013).

using a dredge deployed from the RV Albert Lucas in 20- to 25-m water depth.

\section{Shell preparation and growth increment analysis}

In total, 24 specimens of different sizes (and ontogenetic ages) were selected from those that had been collected alive. By choosing different sizes of shells (i.e. shells that settled at different times), it was possible to ensure that juvenile increments were available for an extended and continuous period of time.

A 3- to 4-cm wide section was cut from each shell from the hinge through to the ventral margin using a diamond tipped blade mounted on a rotary grinding saw, making sure that the apex of the umbone and the axis of maximum growth were included in the section. The cut section was then embedded into polyester resin (Sody 33, Escil, France) and placed in an oven set at $30^{\circ} \mathrm{C}$ until dry before a final section was cut with a precision saw (Struers Secotom-10) along the axis of maximum growth. The cut surface was ground using silicon carbon paper (F grit 800-4000) using a mechanical grinding machine (Struers TegraPol-35) and polished by hand using $3 \mu \mathrm{m}$ diamond paste. The polished shell sections were then etched in $0.1 \mathrm{M} \mathrm{HCl}$ for $90 \mathrm{~s}$, soaked in a water bath and left to air dry (Ramsay et al., 2000, 2001; Reynolds et al., 2013). In order to identify the annual increments and assign calendar years to each of them, acetate peel replicas were prepared using methods described by Richardson (2001).

The peels were digitally photographed using a Zeiss AxioCam MRc5 digital camera with a Zeiss Lumar.V12 stereomicroscope under transmitted light and $40 \times$ and $80 \times$ magnification. The software AxioVision V4.9.1 was used to construct photo mosaics from these photographs. The growth increment measurements were taken through the hinge rather than the ventral margin portion as the hinge provides a more concise, yet equally clear and complete, record of the entire growth record (Ramsay et al., 2000). Standard sclerochronological statistical techniques were used to crossdate the G. glycymeris growth increment series to ensure accuracy of the calendar years assigned to each increment (Jones et al., 1989; Marchitto et al., 2000; Schöne et al., 2003; Scourse et al., 2006; Helama et al., 2007). More details of the crossdating methods used can be found in Featherstone et al. (2017).

The section was then cut again using the precision saw to 3- to 6-mm thick sections and polished again with $3 \mu \mathrm{m}$ diamond paste. The goal of this was to obtain a thick cross-section to sample shell powder (here aragonite) for $\delta^{18} \mathrm{O}$ analysis. The polished slab was rinsed several times ultrasonically with demineralized water prior to sampling for isotopic composition. Calendar dates were marked next to each increment in the margin by scratching the resin in 


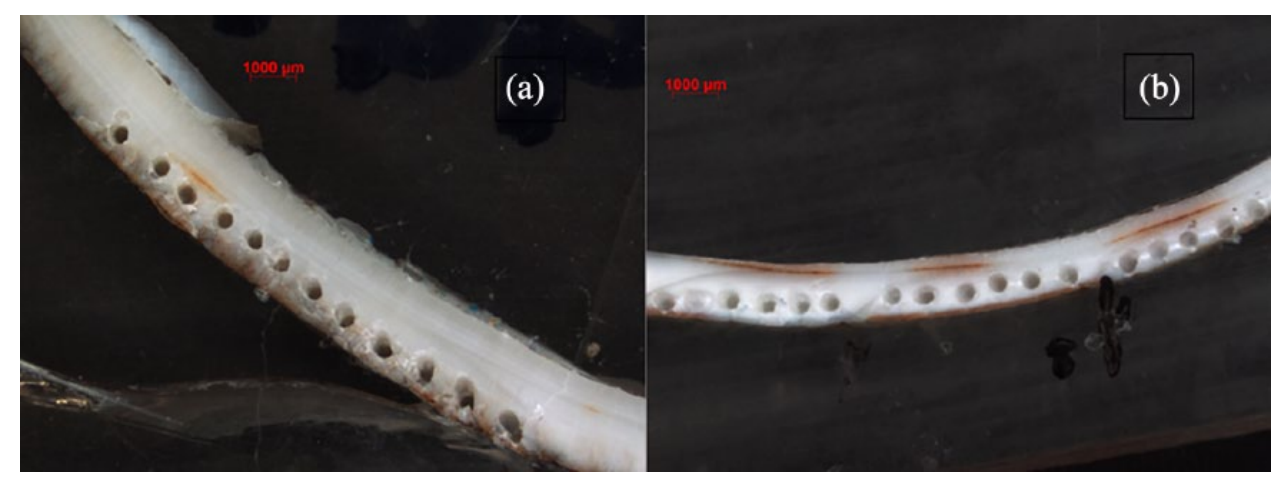

Figure 2. Examples of drill sampling on the prismatic shell layer for ${ }^{18} \mathrm{O}$ analysis. Specimens (a) I4IIII007 and (b) I4I2I 022.

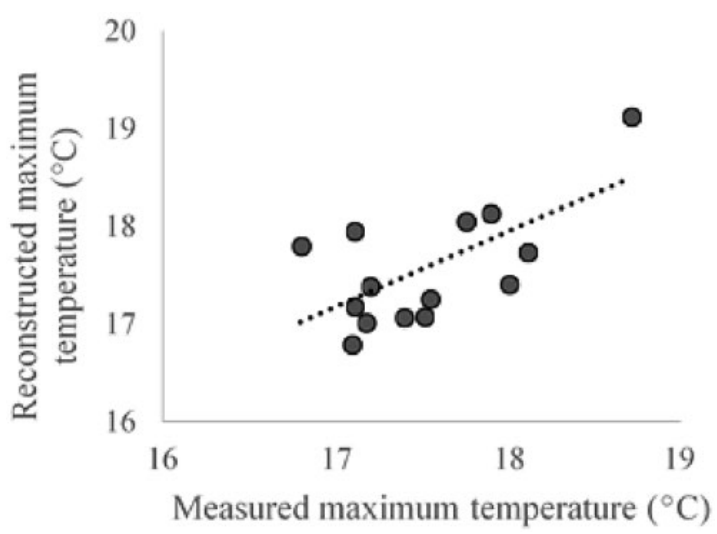

Figure 3. Cross-plot of measured and reconstructed maximum annual temperatures.

order to align them with the increments measured in the much smaller hinge area.

\section{Oxygen isotopic analysis}

Because increments are wider in the early years of growth, the shells were sampled only between the second year and the eighth year of growth to maximize the number of samples taken from each annual increment and thus increase the temporal resolution.

Shell aragonite powder $(n=636)$ was sampled in the direction of growth using an automated high-resolution microsampling device (MicroMill, New Wave Research) equipped with a 300- $\underline{\mu}$ tungsten carbide drill bit (model H71.104.003, Gebr. Brasseler GmbH \& Co. KG, Germany). Between 8 and 33 (average 12) carbonate samples per increment were collected from the outer prismatic layer of each of the 24 shells. Drill holes were ca. $350 \mu \mathrm{m}$ (Figure 2) in diameter and provided aragonite fractions of $\overline{5} 0$ to $120 \underline{\mu g}$ (on average, $94 \underline{\mu g}$ ). Samples were processed in a Thermo Finnigan MAT $25 \overline{3}$ continuous flow-isotope ratio mass spectrometer coupled to Gas Bench II at the Institute of Geosciences, University of Mainz. They were dissolved in water-free phosphoric acid in helium-flushed borosilicate exetainers at $72^{\circ} \mathrm{C}(2 \mathrm{~h}$ reaction time $)$. Stable oxygen isotope ratios are reported relative to the Vienna Pee-Dee Belemnite (VPDB) standard based on an NBS-19 calibrated Carrara marble $\left(\delta^{18} \mathrm{O}=-1.91 \%\right)$. The average internal precision error - based on eight individual measurements per sample was $0.06 \%$ and the long-term accuracy $(1 \sigma)$, based on 421 blind measurements of NBS-19, was $\pm 0.04 \%$.

In order to determine past temperatures using $\delta^{18} \mathrm{O}_{\text {shell }}$, we used a palaeothermometry equation developed by Royer et al. (2013), calibrated for aragonitic G. glycymeris shells from the Bay of Brest

$$
\begin{aligned}
& T\left({ }^{\circ} \mathrm{C}\right)=18.11( \pm 0.13)-2.66( \pm 0.15) \times \\
& \left(\delta^{18} \mathrm{O}_{\text {shell }}-\delta^{18} \mathrm{O}_{\text {water }}\right)
\end{aligned}
$$

Using this equation requires shell oxygen isotope data (VPDB) that are not adjusted for differences in acid fractionation factors of aragonite (shell) and calcite (standards). For more detailed explanation of this correction, see Füllenbach et al. (2015).

The water oxygen isotope value (V-SMOW) in the Bay of Brest was estimated using the linear relationship between $\delta^{18} \mathrm{O}_{\text {water }}$ and salinity (S) (measured at SOMLIT) as reported by Chauvaud et al. (2005)

$$
\delta^{18} \mathrm{O}_{\text {water }}=0.164( \pm 0.001) \times S-5.38( \pm 0.02)
$$

The salinity term used in Eq. 2 represents the average from May to October between 1998 and 2011, and ranges from 34.69 to $35.24(1 \sigma=0.16)$.

\section{Reconstruction of growth rate}

A long-term SST reconstruction was developed based on $\delta^{18} \mathrm{O}_{\text {shell }}$ taken from increments formed between 1966 and 2011. The isotope data were aligned to the SOMLIT SST curve using the $\delta^{18} \mathrm{O}_{\text {shell }}$-derived SST, assuming average $\delta^{18} \mathrm{O}$ water, so the best fit was obtained. It was then realigned based on the actual $\delta^{18} \mathrm{O}_{\text {water }}$ calculated using Eq. 2 until the $r$ values no longer increased. Reconstruction of the seasonal growth rate was then clarified by using the sinusoidal temperature variation model (Judd et al., 2018), adjusted to utilize Eq. 1 rather than the default equation developed by Grossman and $\mathrm{Ku}$ (1986). This model can derive estimated growth rates using only serially sampled oxygen isotope data under the assumption that the annual variations in temperature are sinusoidal (Judd et al., 2018).

\section{Results}

\section{Determination of the seasonal timing and rate of shell growth}

When the equation of Grossman and $\mathrm{Ku}$ (1986) was used to recreate temperature between 1998 and 2011, significant differences were observed between measured and predicted values of $\delta^{18} \mathrm{O}_{\text {shell }}$ values. Due to this, all further analysis was done using the equation quoted by Royer et al. (2013; Eq. 1), which gave reconstructed temperatures in line with those measured by SOMLIT-Brest.

Reconstructed temperatures with Eq. 1 were compared with the temperatures recorded by the SOMLIT monitoring station between 1998 and 2010, highlighting that annual maxima are recorded in the shells with a good fidelity (Pearson's correlation: $p=0.002, r=0.760$; Figure 3 ), whereas annual minima are not 


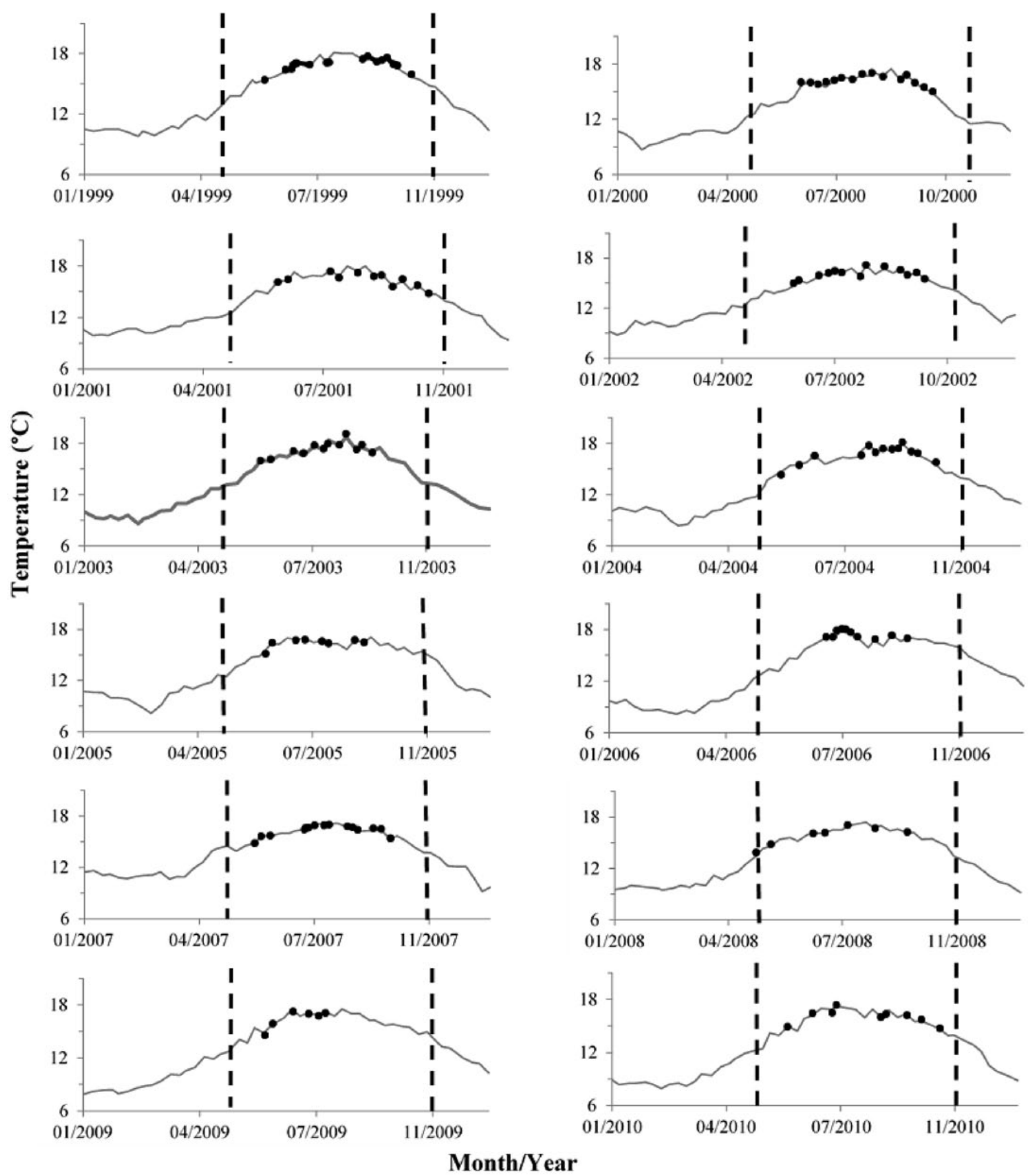

Figure 4. Time series of oxygen isotope-derived temperatures from nine different shells calculated from Eq. I (black dots) and measured temperatures in the Bay of Brest (grey line) separated by each sampling year (1999-2010). Vertical hashed lines represent the first week of May and the last week of October, corresponding to the growing season determined by Royer et al. (2013). The reconstructed temperature points are constrained to follow the instrumental temperatures as closely as possible.

recorded in the shells. As with Royer et al. (2013), it was found that the period of growth for G. glycymeris in the Bay of Brest lasts from May to October (Figure 4), though it should be taken into account that, in order to avoid contamination, a distance of $350 \mu \mathrm{m}$ was left unsampled between the growth lines and the first and last sample in each increment. The full range of reconstructed temperatures was $13.9^{\circ} \mathrm{C}$ to $19.1^{\circ} \mathrm{C}$ (Figure 5b).

Using the model developed by Judd et al. (2018), it was possible to determine more accurate dates for the start and end of the growth cycle for all years (1966-2010). The modelled start of growth ranged from 10 May to 6 July, with most start dates in June, and the modelled end of growth ranged from 10 August to 28 October. The average measured growing season was 106 days long, with a minimum of 53 days in 2009 and a maximum of 136 days in 2010. The shortest modelled growing season was in 1984 and consisted of 54 days, and the longest was 154 days in 1998 . The average modelled growth season was 115 days long.

The reconstructed temperatures were aligned annually using the sinusoidal curves generated by using the model created by Judd et al. (2018). This can be seen visually in Figure 5a. The modelled first day and the last day of growth for each year can be found in more detail in Appendices 1 and 2 in the Supplemental Material (available online).

\section{Expanding the temperature reconstruction}

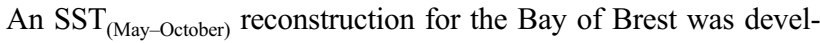
oped to cover the time interval 1966-2010. Eq. 1 was applied to oxygen isotope ratios taken from the juvenile growth increments of 24 specimens with overlapping lifespans (Figure 6). Due to salinity 


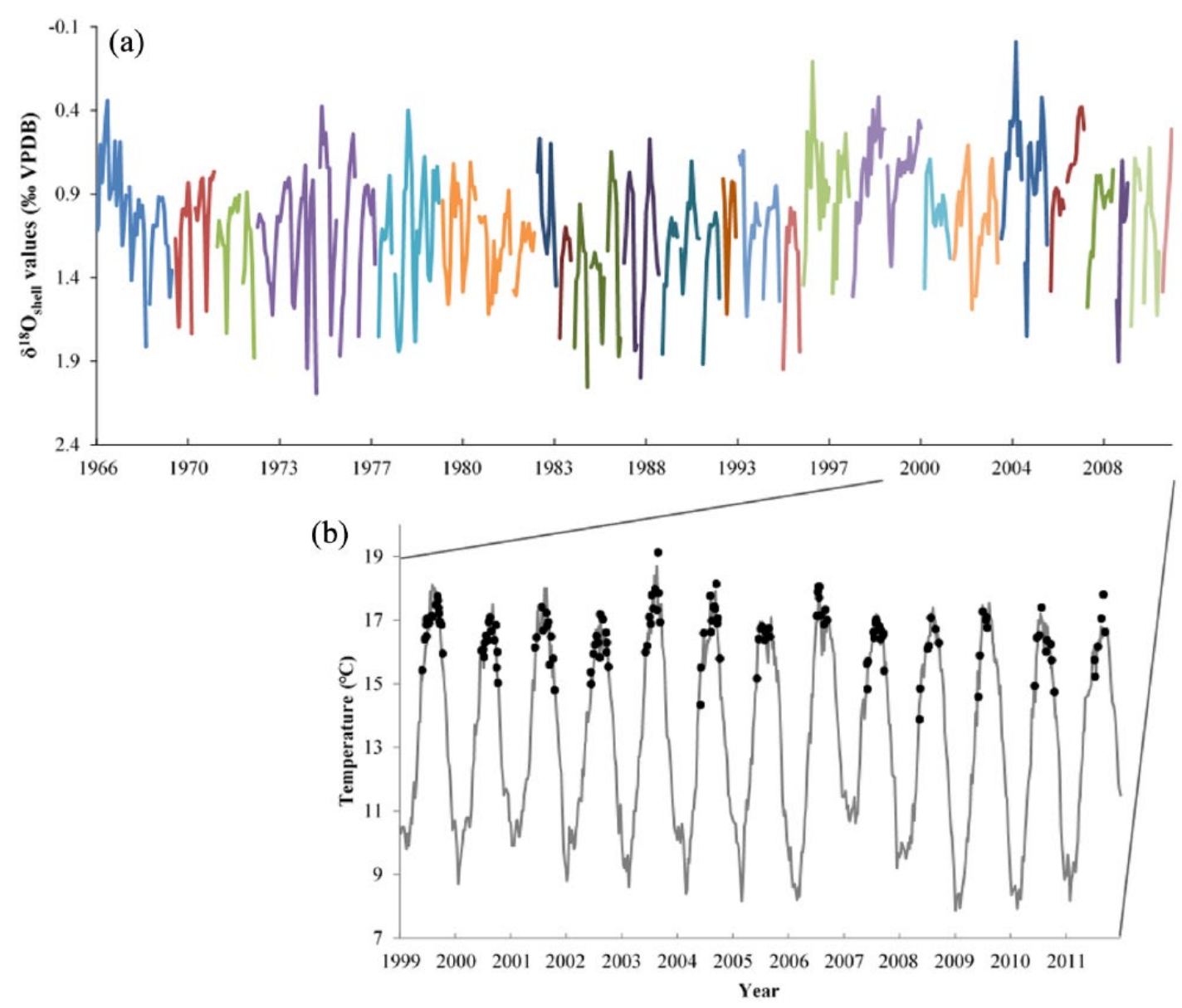

Figure 5. $\delta^{18}$ Oshell values and reconstructed temperatures derived using Eq. I.(a) Inverted $\delta^{18}$ Oshell values taken from juvenile growth portions of 24 shells spanning 1966-20I I. Each line indicates a different shell. (b) Time series of oxygen isotope-derived temperature from the palaeotemperature equation (black dots) and measured temperatures in the Bay of Brest (grey line) from 1999 to 201 I.

varying by 2.39 between May and October, there was an uncertainty of $\pm 0.44^{\circ} \mathrm{C}$ (calculated using Eq. 2). The reconstructed temperatures show that maximum seawater temperatures through the growth season greatly varied over time, with a 'cool' phase until 1995 (mean maximum: $16.0 \pm 0.1^{\circ} \mathrm{C}$ ) and a 'warmer' phase afterwards (mean maximum: $16.5 \pm 0.2^{\circ} \mathrm{C}$; $t$-test; $p<0.001, t=$ $-4.267)$. The maximum temperature reached before 1995 was $17.9^{\circ} \mathrm{C}$ in 1966 whereas, after 1995 , the maximum temperature was $19.1^{\circ} \mathrm{C}$ (Figure $7 \mathrm{a}$ ).

This shift was also apparent for the mean reconstructed temperatures that prevailed between May and October (henceforth referred to as $\left.\mathrm{rSST}_{\text {May-October }}\right)$. The maximum mean $\mathrm{rSST}_{\text {May-October }}$ was $16.7^{\circ} \mathrm{C}$ before 1995 and $17.5^{\circ} \mathrm{C}$ afterwards (Figure $7 \mathrm{~b}$ ). The years that had the warmest days, according to the $\mathrm{rSST}_{\text {May-October }}$ were 1996 and 2003, while the years with the coldest days during the growth period were 1973 and 1984 (Figure 7a). This is reflected in the $\mathrm{rSST}_{\text {May-October }}$ when averaged which show that the overall warmest summers were in 2003 and 2006, while the coldest summer was in 1984 (Figure 7b). As there was no reconstructed temperature recorded below $13.2^{\circ} \mathrm{C}$ (Figure 7a), we can infer that this is the lowest temperature at which shell growth can occur in G. glycymeris in the Bay of Brest. Over the period of 1966-2010, the reconstructed temperatures between May and October (Figure 7b) show a linear warming trend of $0.07^{\circ} \mathrm{C} /$ decade $(95 \%$ confidence interval $(\mathrm{CI})$ ).

\section{Relationship with climate indices}

The annual average reconstructed SST was derived for all annual increments from 1966 to 2010 and linearly regressed against an index of $\mathrm{NAO}_{\text {winter }}$ obtained from the National Centers for Environmental Information (NCEI-NOAA). The indices for the EAP, provided by the Climate Prediction Center (NOAA), and the Atlantic SPG, reconstructed with the Miami Isopycnic Coordinate Ocean Model (MICOM) by Hátún et al. (2005), are annual averages. Any correlations found between SST in the growing season and $\mathrm{NAO}_{\text {winter }}$ will likely be lagged by one year. The same can be said for the EAP (Conrad et al., 2003; Wibig, 1999).

A significant negative correlation was found between the $\mathrm{rSST}_{\text {May-October }}$ and the SPG index $(r=-0.500, p=0.001)$. As the SPG circulation increased in 1981, temperature decreased with the opposite occurring in 1995 (Figure 8a). Overall, the two plots trend in opposite directions, with a change in 1995. Before then, the SPG had a weak increasing trend (while the reconstructed temperature was slightly decreasing). After 1996, the SPG weakened rapidly and temperatures in the Bay of Brest increased.

A positive correlation was found between the $\mathrm{rSST}_{\text {May-October }}$ and the EAP index when lagged by one year $(r=0.460, p=0.002$; Figure $8 b$ ). This means that the EAP strength in 2000 , for example, would have an effect on temperature in the Bay of Brest in 2001. No correlation was found between $\mathrm{rSST}_{\text {May-October }}$ and the $\mathrm{NAO}_{\text {winter }}$ index $(r=-0.261, p=0.114$; Figure 8c), although the temperature increase in 1996 coincided with a switch of the $\mathrm{NAO}_{\text {winter }}$ into its negative phase. This switch in 1995/1996 is present in some form in all the studied climate indices as this is the point at which the SPG began to decline (Figure 8a), the EAP entered its most positive phase (Figure $8 \mathrm{~b}$ ) and the NAO entered a more negative phase (Figure 8c).

\section{Discussion}

By comparing and relating G. glycymeris temperature reconstructions with similarly sensitive climate indices, it is possible to reconstruct palaeoceanographic and atmospheric variability over 


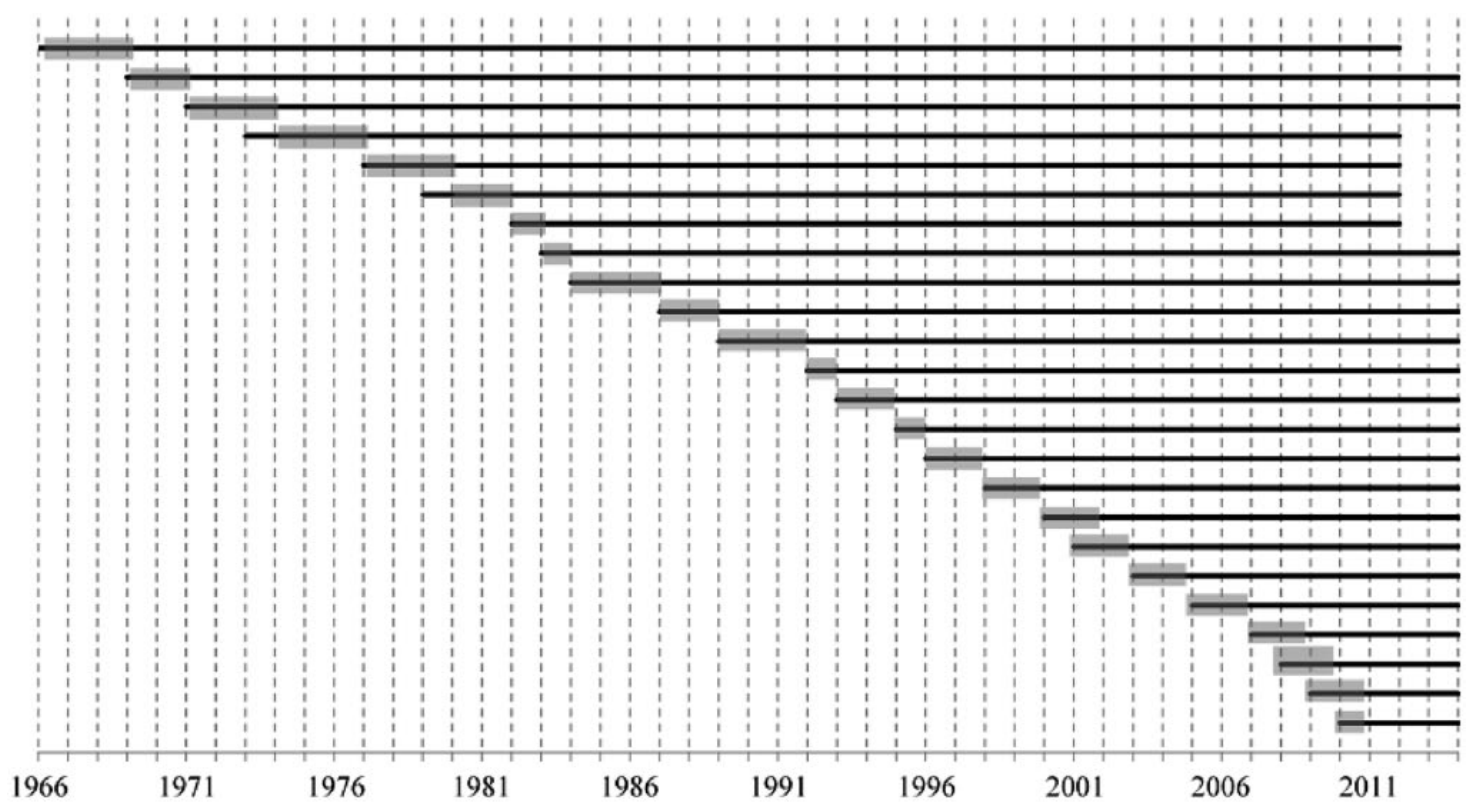

Figure 6. Lifespans of the 24 shells analysed for oxygen isotope composition. Grey sections indicate growth increments drilled for stable isotope analysis.
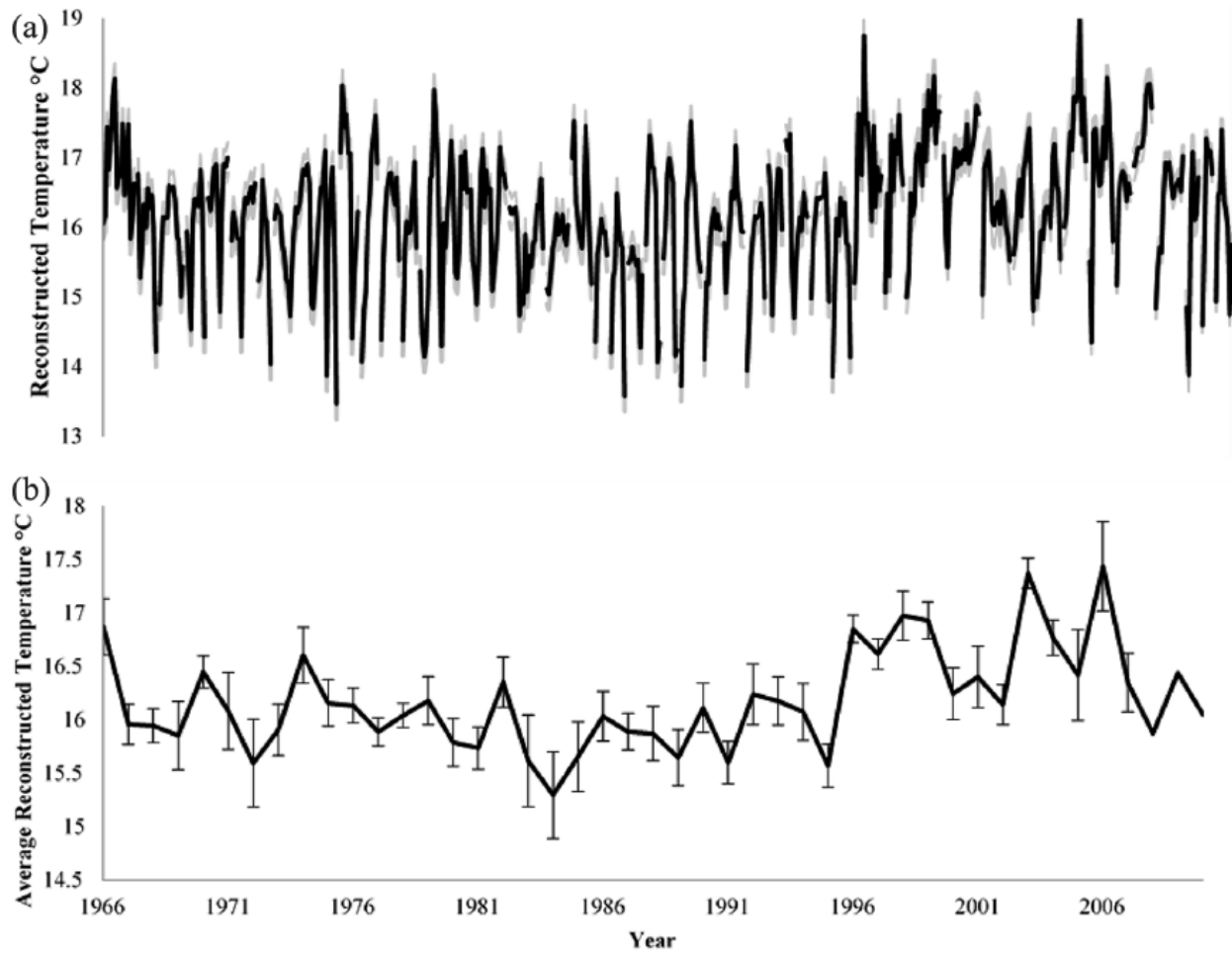

Figure 7. Oxygen isotope reconstructions. (a) Time series of oxygen isotope-derived temperature at the Bay of Brest from 1966 to 2010 (black line) during the growing season of May-October. Grey shading represents the uncertainty related to the use of an average $\delta^{18} \mathrm{Owater}$ value; (b) Average oxygen isotope-derived temperatures during the annual growing season. Error bars represent errors in Eqs $I$ and 2 in addition to machine error.

the late Holocene or even as far back as the early Oligocene where Glycymeris species have been found in the fossil record (Walliser et al., 2015). Such temperature reconstructions are often useful for the calibration of predictive numerical climate models (Mann, 2002).

Our study showed a negative correlation between the SPG index and the $\mathrm{rSST}_{\text {May-October }}$ in the Bay of Brest (Figure 8a), with the SPG increasing in strength between the late 1960s and early 1990 s, before declining sharply from 1995 to the early 2000 s. This is in agreement with other studies which show rapid weakening since the mid-1990s (Corbière et al., 2007; Metzl et al., 2010; Yang et al., 2016).

Previous studies suggest that the recent weakening SPG has increased the likelihood of several climate impacts including more frequent hurricanes (Msadek et al., 2014) as well as a larger number of wet and warm summers over much of Europe (MacLeod et al., 2016). Hermanson et al. (2014) predicted a strengthening of the SPG after a warm spike in 2003 (as is shown in our reconstructed temperatures; Figure $7 \mathrm{~b}$ ) but not a complete reversal to previous cold conditions. As a result, they expect the 


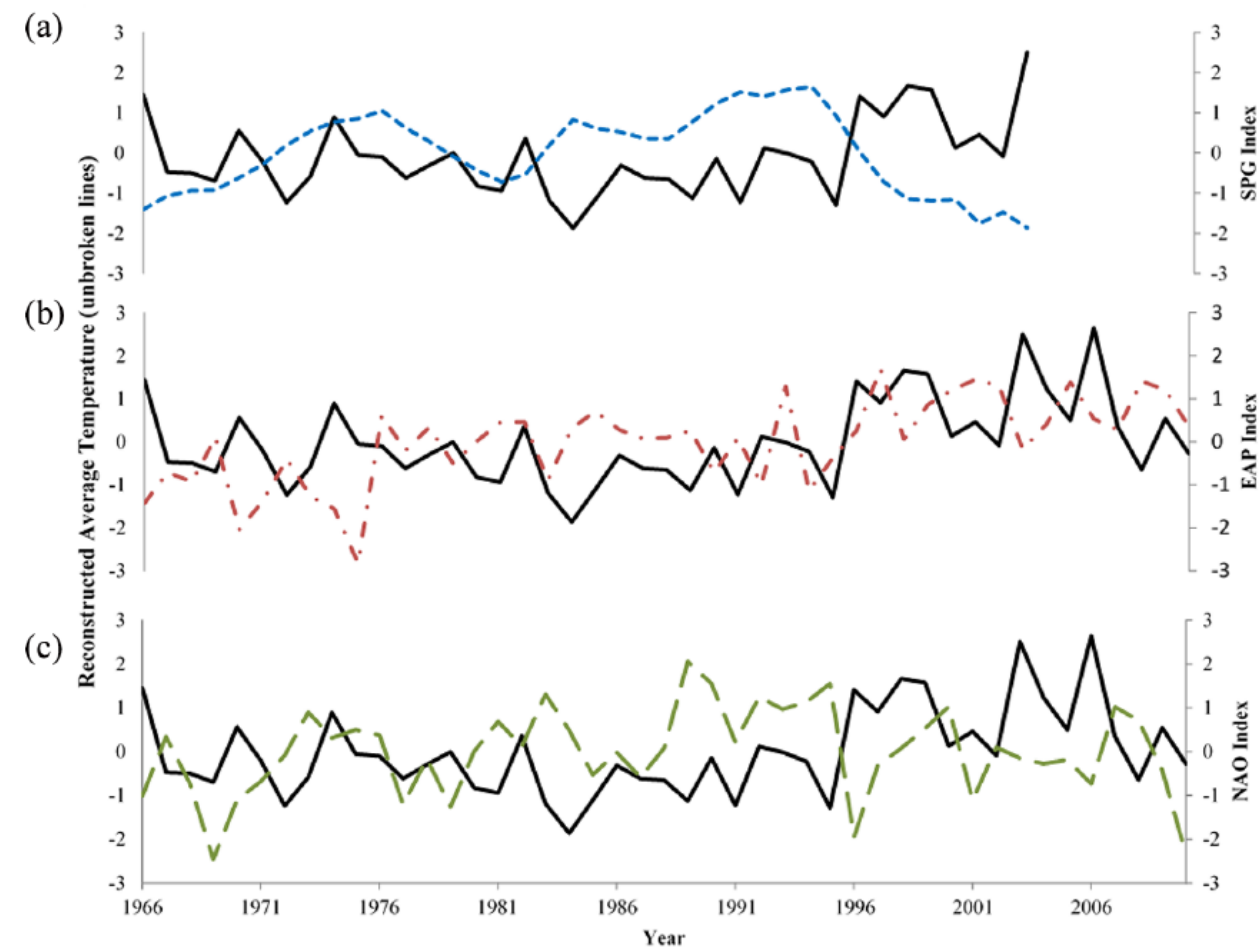

Figure 8. Comparison of the standardized indices of annual average reconstructed temperature (unbroken lines) and various climate modes: SPG (dotted line: a), EAP (dash/dot line: b) and NAO (dashed line: $c$ ).

Table I. Associations of the positive and negative phases of the NAO and EAP with Western European climate.

\begin{tabular}{|c|c|c|}
\hline & NAO & EAP \\
\hline $\begin{array}{l}\text { Positive } \\
\text { phase }\end{array}$ & $\begin{array}{l}\text { High air temperature } \\
\text { Lower precipitation } \\
\text { Strengthening of the subpolar } \\
\text { gyre - lower surface salinity }\end{array}$ & $\begin{array}{l}\text { Above average SST } \\
\text { Higher precipitation }\end{array}$ \\
\hline $\begin{array}{l}\text { Negative } \\
\text { phase }\end{array}$ & $\begin{array}{l}\text { Lower air temperature } \\
\text { Higher precipitation and more } \\
\text { frequent storm events } \\
\text { Weakening of the subpolar } \\
\text { gyre - higher surface salinity }\end{array}$ & $\begin{array}{l}\text { Below average SST } \\
\text { Lower precipitation }\end{array}$ \\
\hline
\end{tabular}

NAO: North Atlantic Oscillation; EAP: East Atlantic Pattern; SST: sea surface temperature.

climate impacts previously mentioned that relate to a weak SPG to persist but become less frequent. Although there are only 7 years present in our reconstruction after 2003, in Figure $7 \mathrm{~b}$ we can see temperatures fluctuate and peak again in 2006 before somewhat settling for another four years. Caesar et al. (2018) predict that the AMOC will continue to weaken in the future, therefore the SPG will continue to cool which will result in warmer summers and increased storminess in Europe.

The year 2003 (the warmest summer in the period under study; Figure 5b) is interesting from a meteorological perspective. Reichstein et al. (2007) conclude that the perceived heatwave was rather a drought spell for most of the biosphere, although our data show that the temperature was also abnormally high in North West France. Schär et al. (2004) suggest, from a modelling point of view, that the 2003 heatwave can be regarded as an indication of possible future climate conditions that will be warmer and with more extremes.

Tréguer et al. (2014) attributed the changes of $\operatorname{SST}_{\text {(winter) }}$ in the Bay of Brest to fluctuations of the NAO. They used data collected by SOMLIT-Brest and compared temperature anomalies with the NAO index from the period 1998-2015. The dissimilarity in results between our study and theirs is most likely due to the seasonal difference between studies. G. glycymeris grow only between May and October (Royer et al., 2013), completely missing the winter months studied by Tréguer et al. (2014). Any potential relationship between reconstructed temperatures and the winter NAO would likely be lagged by a year, which is not the case (Figure 8c)

Tréguer et al. (2014) accepted that the period covered by their study was not sufficient to provide a complete picture of the climate processes influencing the Bay of Brest; given the much longer reconstruction presented here, we are able to suggest an alternative hypothesis. After 1997, the NAO and the SPG started acting, overall, in phase with each other, with important turning points in 1994 and 1995, respectively.

Precipitation is thought to be the driving factor of sea surface salinity in areas influenced by the SPG (Grist et al., 2015). As such, salinity in the Bay of Brest will be expected to change through the aforementioned NAO phases (Table 1). In this study, salinity was only recorded from 1998 to present, which means that a change in the $\mathrm{NAO}^{+}$forcing may not have been completely observed. Also, an average salinity from 1998 to 2011 was used to reconstruct temperatures further back in time, using Eq. 1. With this caveat, the fact that the reconstructed temperatures are consistent with the same climate signals both before and after 1998 (Figure $8 \mathrm{a}$ and b) allows us to infer that the salinity in the Bay of Brest did not change significantly through the reconstructed time frame.

The EAP index has also been shown to correlate with the rSST $_{\text {May-October }}$ of the Bay of Brest. The EAP reflects climate patterns at lower latitudes than the NAO and SPG and contains a strong subtropical link (Santana-Casiano et al., 2007). The positive phase of the EAP is usually associated with high SST throughout Europe in all months of the year (Table 1) and was associated by Cannaby and Hüsrevoğlu (2009) with a recent warm anomaly in Irish waters. As the EAP and SST in the Bay of Brest are correlated in our study, we suggest that the EAP represents pressure patterns that affect the SST and oceanatmosphere heat and freshwater fluxes.Cannaby and Hüsrevoğlu (2009) state, 
within the central North Atlantic basin, including the SPG and Subpolar Front, the Atlantic Multidecadal Oscillation and EAP patterns are out of phase. Due to this, the current warming of the SPG associated with the current positive phase of the Atlantic Multidecadal Oscillation is inhibited by the concurrent positive phase of the EAP.

\section{Growth season of G. glycymeris in the Bay of Brest}

Schöne et al. (2004) defined the growth season of bivalve shells as the months of the strongest correlation between growth and measured SST. Using this definition, Brocas et al. (2013) established that the growth season for G. glycymeris from the Isle of Man to be between January and September. This is a much longer period of growth than found in the Bay of Brest where the growth of G. glycymeris is found to be predominantly between May and October in this study and Royer et al. (2013). However, in this study, this growth season can only be taken as a rough estimate as $350 \mu \mathrm{m}$ of shell was left unsampled at the beginning and end of the growth increment to avoid accidentally contaminating the sample with the dense material of the increment line.

In order to pin down the period of growth more accurately, the model developed by Judd et al. (2018) was used; however, this model is not infallible in real-world simulations. The model assumes that there is no uncertainty in the distances measured between samples, that there is no noise in the isotope sampling, that the time averaging is correct and that the accuracy of the modelled seasonal amplitude is correct (Judd et al., 2018). Judd et al. (2018) theorized that in natural systems, the dates could be underestimated even when the isotope-derived temperatures are known for over $75 \%$ of the sampled range. In this study, the temperature range was constrained by setting a minimum value for the temperature amplitude and the date of the mean annual temperature, which minimized model-data mismatch and variation regardless of the relationship between phases of temperature and growth rate. As such, the model is as accurate as possible but is still subject to real-world constraints, and the final dates derived must take this into account.

\section{Conclusion}

Temperatures in the Bay of Brest, between May and October, can be reconstructed from the $\delta^{18} \mathrm{O}$ values of G. glycymeris shells using the palaeotemperature equation (Eq. 1) of Royer et al. (2013). By using $\delta^{18} \mathrm{O}$ in longer lived, or fossil, shells that can be crossdated into the chronology, it should be possible to extend the temperature reconstruction for several decades, or even a century or more.

The climate systems exerting the greatest influence on SST of the Bay of Brest are the EAP and the SPG. The SPG influences air temperature in Northern Europe and the EAP is an indicator of water temperature in Southern Europe, suggesting that the Bay of Brest is an area where the signals of these two climate systems interact. Temperature archives from this locality can therefore be used as proxies for both the SPG and EAP, and long-term temperature reconstructions can provide a unique insight into how these climate systems interacted prior to observations. However, the overlap between the SPG and EAP in this area complicates the interpretation of the temperature signal, as we would first need to know which mode was more dominant at any given time. To obtain full value from this proxy, it needs to be interpreted in combination with other archives that contain an uncontaminated signal of the SPG or the EAP.

\section{Funding}

The author(s) disclosed receipt of the following financial support for the research, authorship, and/or publication of this article: This work was supported by the European Union Seventh Framework Programme FP7-PEOPLE-2013-ITN (grant number: 604802).

\section{ORCID iD}

Amy M Featherstone iD https://orcid.org/0000-0001-6368-3820

\section{Supplemental material}

Supplemental material for this article is available online.

\section{References}

Berthou P, Blanchard M, Noel P et al. (1986) The analysis of stable isotopes of the shell applied to the determination of the age of four bivalves of the Normano-Breton Gulf, Western Channel. ICES K 16: 1-13.

Bonan GB (2008) Forests and climate change: Forcings, feedbacks, and the climate benefits of forests. Science 320(5882): 1444-1449.

Braconnot P, Harrison SP, Kageyama M et al. (2012) Evaluation of climate models using palaeoclimatic data. Nature Climate Change 2: 417-424.

Brocas WM, Reynolds DJ, Butler PG et al. (2013) The dog cockle, Glycymeris glycymeris (L.), a new annually-resolved sclerochronological archive for the Irish Sea. Palaeogeography, Palaeoclimatology, Palaeoecology 373: 133-140.

Butler PG, Richardson CA, Scourse JD et al. (2010) Marine climate in the Irish Sea: Analysis of a 489-year marine master chronology derived from growth increments in the shell of the clam Arctica islandica. Quaternary Science Reviews 29: 1614-1632.

Butler PG, Scourse JD, Richardson CA et al. (2009) Continuous marine radiocarbon reservoir calibration and the ${ }^{13} \mathrm{C}$ Suess effect in the Irish Sea: Results from the first multi-centennial shell-based marine master chronology. Earth and Planetary Science Letters 279: 230-241.

Caesar L, Rahmstorf S, Robinson A et al. (2018) Observed fingerprint of a weakening Atlantic Ocean overturning circulation. Nature 556: 191-196.

Cannaby H and Hüsrevoğlu YS (2009) The influence of low-frequency variability and long-term trends in North Atlantic sea surface temperature on Irish waters. ICES Journal of Marine Science 66(7): 1480-1489.

Chauvaud L, Lorrain A, Dunbar RB et al. (2005) Shell of the Great Scallop Pecten maximus as a high-frequency archive of paleoenvironmental changes. Geochemistry, Geophysics, Geosystems 6(8). Available at: https://agupubs.onlinelibrary. wiley.com/doi/full/10.1029/2004GC000890.

Conrad KF, Woiwod IP and Perry JN (2003) East Atlantic teleconnection pattern and the decline of a common arctiid moth. Global Change Biology 9(2): 125-130.

Corbière A, Metzl N, Reverdin G et al. (2007) Interannual and decadal variability of the oceanic carbon sink in the North Atlantic Subpolar Gyre. Tellus B 59: 168-178.

Dawson A, Hickey K, Holt T et al. (2002) Complex North Atlantic Oscillation (NAO) index signal of historic North Atlantic storm-track changes. The Holocene 12: 363-369.

Featherstone AM, Butler PG, Peharda M et al. (2017) Influence of riverine input on the growth of Glycymeris glycymeris in the Bay of Brest, North-west France. PLoS ONE 12(12): $\mathrm{e} 0189782$.

Füllenbach CS, Schöne BR and Mertz-Kraus R (2015) Strontium/lithium ratio in aragonitic shells of Cerastoderma edule (Bivalvia) - A new potential temperature proxy for brackish environments. Chemical Geology 417: 341-355.

García-Herrera R, Wilkinson C, Koek FB et al. (2005) Description and general background to ships' logbooks as a source of climatic data. Climatic Change 73(1-2): 13-36. 
Grist JP, Josey SA, Jacobs ZL et al. (2015) Extreme air-sea interaction over the North Atlantic Subpolar Gyre during the winter of 2013-2014 and its sub-surface legacy. Climate Dynamics 46(11-12): 4027-4045.

Grossman EL and Ku TL (1986) Oxygen and carbon isotope fractionation in biogenic aragonite: Temperature effects. Chemical Geology: Isotope Geoscience Section 59: 59-74.

Hansen J, Fung I, Lacis A et al. (1998) Global climate changes as forecast by Goddard Institute for Space Studies three-dimensional model. Journal of Geophysical Research: Atmospheres 93: 9341-9364.

Hátún $H$, Sandø AB, Drange $H$ et al. (2005) Influence of the Atlantic subpolar gyre on the thermohaline circulation. Science 309(5742): 1841-1844.

Helama S, Schöne BR, Kirchhefer AJ et al. (2007) Compound response of marine and terrestrial ecosystems to varying climate: Pre-anthropogenic perspective from bivalve shell growth increments and tree-rings. Marine Environmental Research 63(2): 185-199.

Herbaut C and Houssais MN (2009) Response of the eastern North Atlantic Subpolar Gyre to the North Atlantic oscillation. Geophysical Research Letters 36(17). Available at: https:// agupubs.onlinelibrary.wiley.com/doi/full/10.1029/2009GL 039090.

Hermanson L, Eade R, Robinson NH et al. (2014) Forecast cooling of the Atlantic subpolar gyre and associated impacts. Geophysical Research Letters 41(14): 5167-5174.

Hurrell JW, Kushnir Y and Visbeck M (2001) The North Atlantic oscillation. Science 291(6606): 603-605.

Jones DS, Arthur MA and Allard DJ (1989) Sclerochronological records of temperature and growth from shells of Mercenaria mercenaria from Narragansett Bay, Rhode Island. Marine Biology 102: 225-234.

Jones PD, Briffa KR, Barnett TP et al. (1998) High-resolution palaeoclimatic records for the last millennium: Interpretation, integration and comparison with General Circulation Model control-run temperatures. The Holocene 8(4): 455-471.

Jones TD, Lunt DJ, Schmidt DN et al. (2013) Climate model and proxy data constraints on ocean warming across the Paleocene-Eocene Thermal Maximum. Earth Science Reviews 125: $123-145$.

Judd EJ, Wilkinson BH and Ivany LC (2018) The life and time of clams: Derivation of intra-annual growth rates from highresolution oxygen isotope profiles. Palaeogeography, Palaeoclimatology, Palaeoecology 490: 70-83.

MacLeod DA, Cloke HL, Pappenberger F et al. (2016) Improved seasonal prediction of the hot summer of 2003 over Europe through better representation of uncertainty in the land surface. Quarterly Journal of the Royal Meteorological Society 142(694): 79-90.

Mann ME (2002) The value of multiple proxies. Science 297(5586): 1481-1482.

Mann ME, Bradley RA and Hughes MK (1998) Global-scale temperature patterns and climate forcing over the past six centuries. Nature 392: 779-787.

Mann ME, Bradley RS and Hughes MK (1999) Northern hemisphere temperatures during the past millennium: Inferences, uncertainties, and limitations. Geophysical Research Letters 26(6): 759-762.

Mann ME, Zhang Z, Rutherford S et al. (2009) Global signatures and dynamical origins of the Little Ice Age and Medieval Climate Anomaly. Science 326(5957): 1256-1260.

Marchitto TM, Jones GA, Goodfriend GA et al. (2000) Precise temporal correlation of Holocene mollusk shells using sclerochronology. Quaternary Research 53: 236-246.

Meehl GA, Covey C, Delworth T et al. (2007) THE WCRP CMIP3 Multimodel dataset: A new era in climate change research. Bulletin of the American Meteorological Society 88(9): 1383-1394.

Metzl N, Corbière A, Reverdin R et al. (2010) Recent acceleration of the sea surface $f \mathrm{CO}_{2}$ growth rate in the North Atlantic Subpolar Gyre (1993-2008) revealed by winter observations. Global Biogeochemical Cycles 24(4). Available at: https://agupubs.onlinelibrary.wiley.com/doi/ full/10.1029/2009GB003658.

Moberg A, Sonechkin DM, Holmgren K et al. (2005) Highly variable Northern Hemisphere temperatures reconstructed from low- and high-resolution proxy data. Nature 433: 613-617.

Msadek R, Delworth TL, Rosati A et al. (2014) Predicting a decadal shift in North Atlantic climate variability using the GFDL forecast system. American Meteorological Society 27: 6472-6496.

Murphy JM, Sexton DMH, Barnett DN et al. (2004) Quantification of modelling uncertainties in a large ensemble of climate change simulations. Nature 430: 768-772.

Pollack HN and Huang S (2000) Climate reconstruction from subsurface temperatures. Annual Review of Earth and Planetary Sciences 28: 339-365.

Raimonet M, Ragueneau O, Andrieux-Loyer F et al. (2013) Spatio-temporal variability in benthic silica cycling in two macrotidal estuaries: Causes and consequences for local to global studies. Estuarine and Coastal Shelf Science 119: 31-43.

Ramsay K, Kaiser MJ, Richardson CA et al. (2000) Can shell scars on the dog cockles (Glycymeris glycymeris L.) be used as an indicator of fishing disturbance? Journal of Sea Research 43(2): 167-176.

Ramsay K, Richardson CA and Kaiser MJ (2001) Causes of shell scarring in dog cockles Glycymeris glycymeris L. Journal of Sear Research 45(2): 131-139.

Reichstein M, Ciais P, Papale D et al. (2007) Reduction of ecosystem productivity and respiration during the European summer 2003 climate anomaly: A joint flux tower, remote sensing and modelling analysis. Global Change Biology 13(3): 634-651.

Reynolds DJ, Butler PG, Williams SM et al. (2013) A multiproxy reconstruction of Hebridean (NW Scotland) spring sea surface temperatures between AD 1805 and 2010. Palaeogeography, Palaeoclimatology, Palaeoecology 386: 275-285.

Reynolds DJ, Hall IR, Slater SM et al. (2017) Reconstructing past seasonal to multicentennial-scale variability in the NE Atlantic Ocean using the long-lived marine bivalve mollusk Glycymeris Glycymeris. Paleoceanography 32(11): 1153-1173.

Richardson CA (2001) Molluscs as archives of environmental change. Oceanography and Marine Biology 39: 103-164.

Royer C, Thébault J, Chauvaud L et al. (2013) Structural analysis and paleoenvironmental potential of dog cockle shells (Glycymeris glycymeris) in Brittany, Northwest France. Palaeogeography, Palaeoclimatology, Palaeoecology 373: 123-132.

Santana-Casiano JM, González-Dávila M, Rueda MJ et al. (2007) The interannual variability of oceanic $\mathrm{CO}_{2}$ parameters in the northeast Atlantic subtropical gyre at the ESTOC site. Global Biogeochemical Cycles 21(1). Available at: https://agupubs. onlinelibrary.wiley.com/doi/full/10.1029/2006GB002788.

Saunders MA, Qian B and Lloyd-Hughes B (2002) Summer snow extent heralding of the winter North Atlantic oscillation. Geophysical Research Letters 30(7): 31.

Schär C, Vidale PL, Lüthi D et al. (2004) The role of increasing temperature variability in European summer heatwaves. Nature 427: 332-336.

Schöne BR, Castro ADF, Feibig J et al. (2004) Sea surface water temperatures over the period 1884-1983 reconstructed from oxygen isotope ratios of a bivalve mollusk shell (Arctica islandica, southern North Sea). Palaeogeography, Palaeoclimatology, Palaeoecology 212(3-4): 215-232. 
Schöne BR, Oschmann W, Kröncke I et al. (2003) North Atlantic oscillation dynamics recorded in shells of a long-lived bivalve mollusk. Geology 31: 1037-1040.

Scourse J, Richardson C, Forsythe G et al. (2006) First cross-matched floating chronology from the marine fossil record: Data from growth lines of the long-lived bivalve mollusc Arctica islandica. The Holocene 16(7): 967-974.

Seager R, Ting M, Held I et al. (2007) Model projections of an imminent transition to a more arid climate in southwestern North America. Science 316(5828): 1181-1184.

Thébault J and Chauvaud L (2013) Li/Ca enrichments in great scallop shells (Pecten maximus) and their relationship with phytoplankton blooms. Palaeogeography Palaeoclimatology Palaeoecology 373: 108-122.
Tréguer P, Goberville E, Barrier N et al. (2014) Large and localscale influences on physical and chemical characteristics of coastal waters of Western Europe during winter. Journal of Marine Systems 139: 79-90.

Walliser EO, Schöne BR, Tütken T et al. (2015) The bivalve Glycymeris planicostalis as a high-resolution paleoclimate archive for the Rupelian (Early Oligocene) of Central Europe. Climate of the past 11: 653-668.

Wibig J (1999) Precipitation in Europe in relation to circulation patterns at the $500 \mathrm{hPa}$ level. International Journal of Climatology 19(3): 253-269.

Yang C, Masina S, Bellucci A et al. (2016) The rapid warming of the North Atlantic Ocean in the mid-1990s in an eddypermitting ocean reanalysis (1982-2013). Journal of Climate 29(15): 5417-5430. 